\title{
(-) castranar OPEN ACCESS \\ Constipation with megacolon in a 36-year-old man: a rare presentation of MEN2B from Sri Lanka
}

\author{
Ashan Rabinath Fernando, ${ }^{1}$ Dharmabandhu Nandadeva Samarasekera, ${ }^{2}$ \\ Rasika Pivithuru Bulathsinghela ${ }^{1}$
}

${ }^{1}$ Surgery, University Surgical Unit, National Hospital of Sri Lanka, Colombo, Sri Lanka ${ }^{2}$ Surgery, University of Colombo Faculty of Medicine, Colombo, Sri Lanka

\section{Correspondence to}

Dr Ashan Rabinath Fernando, ashan.fernando.4@gmail.com

Accepted 13 December 2018

\section{SUMMARY}

Diffuse intestinal ganglioneuromatosis is a rare condition associated with MEN2B. It is also seen in conditions like neurofibromatosis type 1 and Cowden syndrome. This is a report of a patient who underwent total colectomy with end ileostomy creation for a megacolon. He was diagnosed to have diffuse ganglioneuromatosis on histological examination of the resected segment of colon. The definitive management of diffuse ganglioneuromatosis is to resect and anastomose.

\section{BACKGROUND}

Multiple endocrine neoplasia (MEN) is a clinical entity associated with multiple endocrine tumours. ${ }^{1}$ Tumours range from benign to malignant. MEN can be either type 1 or type 2 .

Type 2 is further classified into types $2 \mathrm{~A}$ and $2 \mathrm{~B}$. Type $2 \mathrm{~A}$ is associated with tumours arising from thyroid, parathyroid and adrenal gland, whereas type $2 \mathrm{~B}$ has tumours arising from the thyroid and adrenal gland. Type $2 \mathrm{~B}$ is associated with phenotypic changes like marfanoid body habitus and multiple mucosal neuromas in the eyes and lips. Other causes of marfanoid body habitus include Shprintzen-Goldberg syndrome, Ehlers-Danlos syndrome and Homocystinuria. ${ }^{2}$

Eighty per cent of medullary thyroid cancer occur sporadically and approximately 20\% are inherited with RET (rearranged during transfection) mutation. ${ }^{3}$ MEN2B is associated with a much more virulent form of medullary thyroid cancer than 2A. MEN2B is associated with RET proto-oncogene mutation.

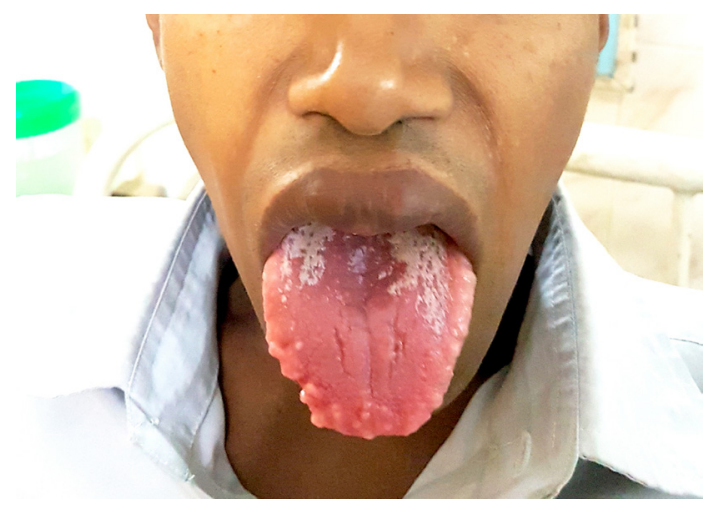

Figure 1 Mucosal neuromas.
Diffuse ganglioneuromatosis is a hamartomatous polyposis condition characterised by mural or transmural proliferation of neural elements in the enteric plexuses. It is seen in conditions like neurofibromatosis-1 (NF-1), MEN2B and Cowden syndrome. ${ }^{4}$ The diagnosis of diffuse ganglioneuromatosis is confirmed by histology. These patients commonly present with altered bowel habits or gastrointestinal bleeding or both.

\section{CASE PRESENTATION}

A 36-year-old man who was diagnosed to have MEN2B presented with worsening constipation and abdominal distension of 3 months duration. $\mathrm{He}$ was diagnosed to have MEN2B while being evaluated for disseminated medullary thyroid cancer at the age of 18 years. The metastatic deposits of medullary thyroid cancer were found, when the patient was evaluated for right side painful inguinal lymphadenopathy.

The patient had clinically significant constipation for 3 months. Despite having constipation for 3 months, due to socioeconomic constraints, the patient only presented when he developed absolute constipation with worsening abdominal distension. He had no other features of bowel obstruction including associated vomiting or abdominal pain.

Even though he required thyroxine replacement following total thyroidectomy for medullary thyroid cancer, he had poor compliance to treatment. The patient also had a neuropathic bladder and was on an indwelling urinary catheter since childhood.

On general examination, the patient was ill looking and in discomfort. He was afebrile. Patient had peripheral pitting oedema. He had marfanoid features including arachnodactyly, high arched palate and pectus excavatum. Mucosal neuromas were seen in the eyelids, lips and tongue (figure 1). On examination of the abdomen, it was grossly distended without features of peritonism. There was flank dullness on percussion and sluggish bowel sounds on auscultation. Digital rectal examination revealed an empty rectum. He was haemodynamically stable.

\section{INVESTIGATIONS}

Initial blood investigations showed a white cell count of $9.6 \times 10^{9} / \mathrm{L} /$ and a haemoglobin concentration of $102 \mathrm{~g} / \mathrm{L}$. His serum creatinine was normal. His serum albumin was low at $22 \mathrm{~g} / \mathrm{L}$ and the thyroid stimulating hormone level was $150 \mathrm{mIU} / \mathrm{L}$ 


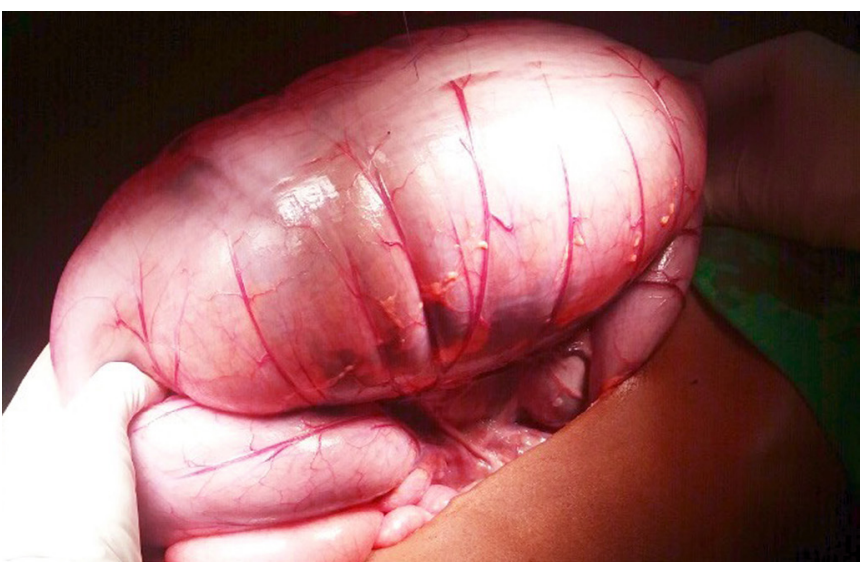

Figure 2 Intraoperative findings of megacolon.

due to poor compliance to thyroxine replacement. The X-ray abdomen showed a grossly dilated large bowel with a maximum diameter of $7 \mathrm{~cm}$. Caecum was dilated to $12 \mathrm{~cm}$. The rectal gas shadows were absent.

\section{DIFFERENTIAL DIAGNOSIS}

1. Colonic tumour.

2. Colonic stricture.

3. Foreign body obstruction.

\section{TREATMENT}

A laparotomy was performed for megacolon with absolute constipation. During the laparotomy, large bowel was grossly dilated with sparing of the rectum and small bowel (figure 2). There were no ischaemic segments. Colon was mobilised from right side proceeding to the left side with hepatic flexure and splenic flexure mobilisation. Total colectomy was done (figures 3 and 4) and an end ileostomy was created.

\section{OUTCOME AND FOLLOW-UP}

He had an uncomplicated postoperative period. The patient was discharged and was followed up in the surgical clinic. Histopathological evaluation of the resected specimen showed 'diffuse ganglioneuromatosis of the colon' (figures 5 and 6).

\section{DISCUSSION}

MEN can be of two types. Type 1 is associated with tumours arising from the pituitary gland, parathyroid and pancreas. Type 2 has $2 \mathrm{~A}$ and $2 \mathrm{~B}$ varieties. MEN2B has several eponyms including Williams-Pollock syndrome, Gorlin-Vickers syndrome and Wagenmann-Froboese syndrome.

MEN type two is associated with RET mutation. The RET mutation can give rise to MEN2A, 2B or familial medullary thyroid cancer. Therefore, clinical entity that manifests via RET mutation depends on the codons and exon that is affected in the RET gene. ${ }^{3}$

Medullary thyroid cancer is almost always present in MEN2B. ${ }^{1}$ Prophylactic thyroidectomy is recommended in patients carrying the RET mutation under the age of 5 years. ${ }^{3}$ MEN2B is associated with a virulent form of medullary thyroid cancer with early dissemination to lymph nodes and early thyroidectomy is warranted. Our patient had disseminated medullary thyroid cancer when it was diagnosed at 18 years, with a positive inguinal lymph nodes. He underwent total thyroidectomy with lymph node block dissection followed by chemotherapy.

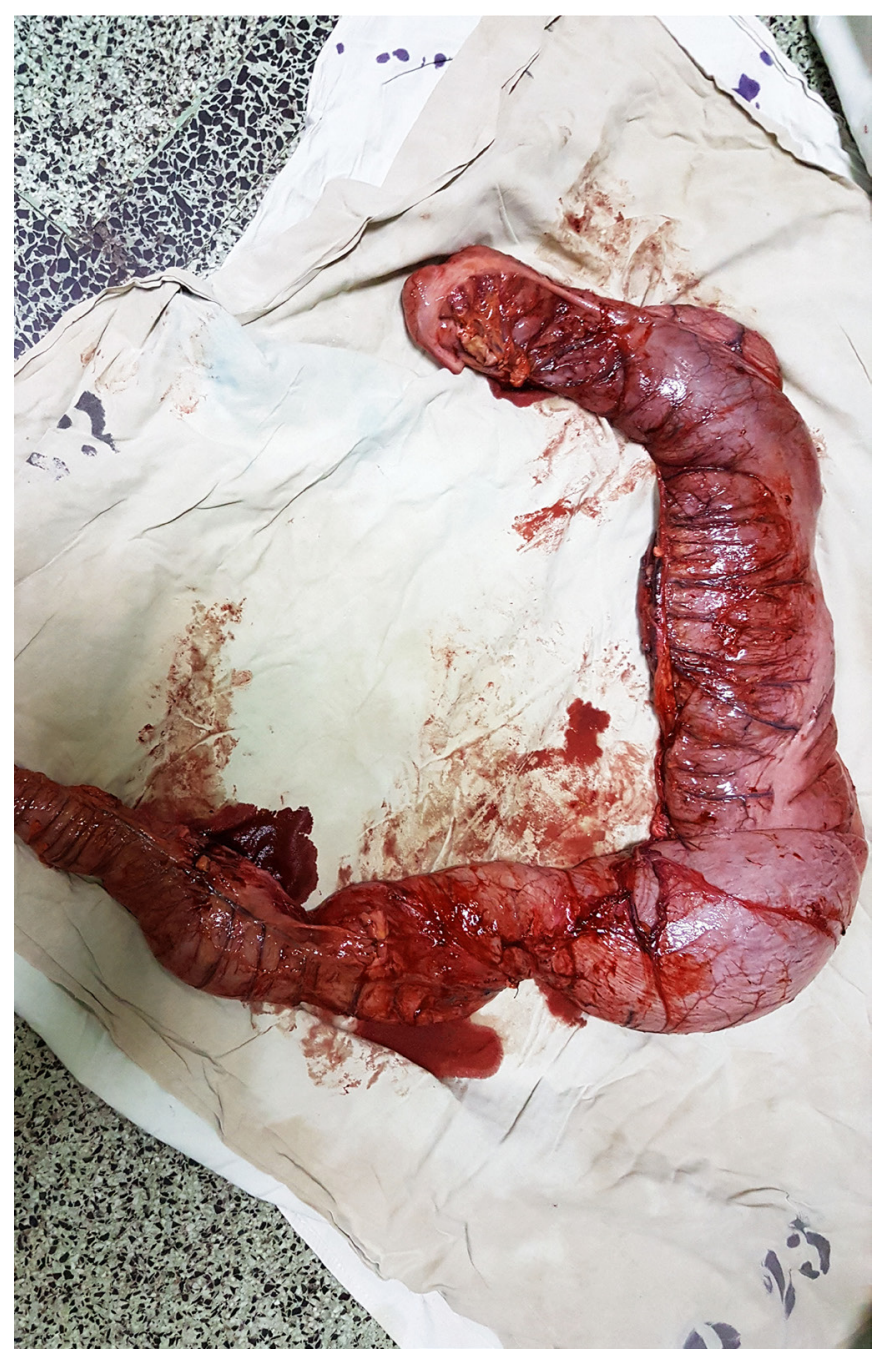

Figure 3 Resected total colectomy specimen.

Surgery with total thyroidectomy is the main mode of management despite metastatic disease. ${ }^{5}$

Intestinal ganglioneuromas are rare benign tumours. It can occur as a localised pathology with a single polypoidal ganglioneuroma or as multiple polyps. Laudari et al described a case report of an isolated ganglioneuroma of the descending colon in a patient who had no associated features of MEN2B or NF-1. ${ }^{6}$ In diffuse ganglioneuromatosis, multiple neuroma can occur in the myenteric and submucosal plexuses. Macroscopically, it manifests as gut wall thickening. ${ }^{7}$ This condition is associated with NF-1, Cowden syndrome and MEN2B syndrome. In MEN2B, myenteric plexus is more involved, whereas submucosal plexus is more involved in NF1. In diffuse ganglioneuromatosis, the entire colon may be involved with sparing of the small bowel. ${ }^{8}$

Diffuse ganglioneuromatosis can present with per rectal bleeding and altered bowel habits such as constipation. Diffuse ganglioneuromatosis can even present with megacolon as seen in this case report and few other reported cases. ${ }^{9}$ This condition responds poorly to medical management and therefore, best managed with surgical resection. ${ }^{7}$ As this condition is very rare, it is usually not included in the differential diagnosis of pseudo-obstruction. The diagnosis of diffuse ganglioneuromatosis is confirmed by histology, ${ }^{7}$ which shows proliferation of nerve cells in the enteric plexuses. In most case reports, diffuse ganglioneuromatosis with MEN2B presents early in childhood with 


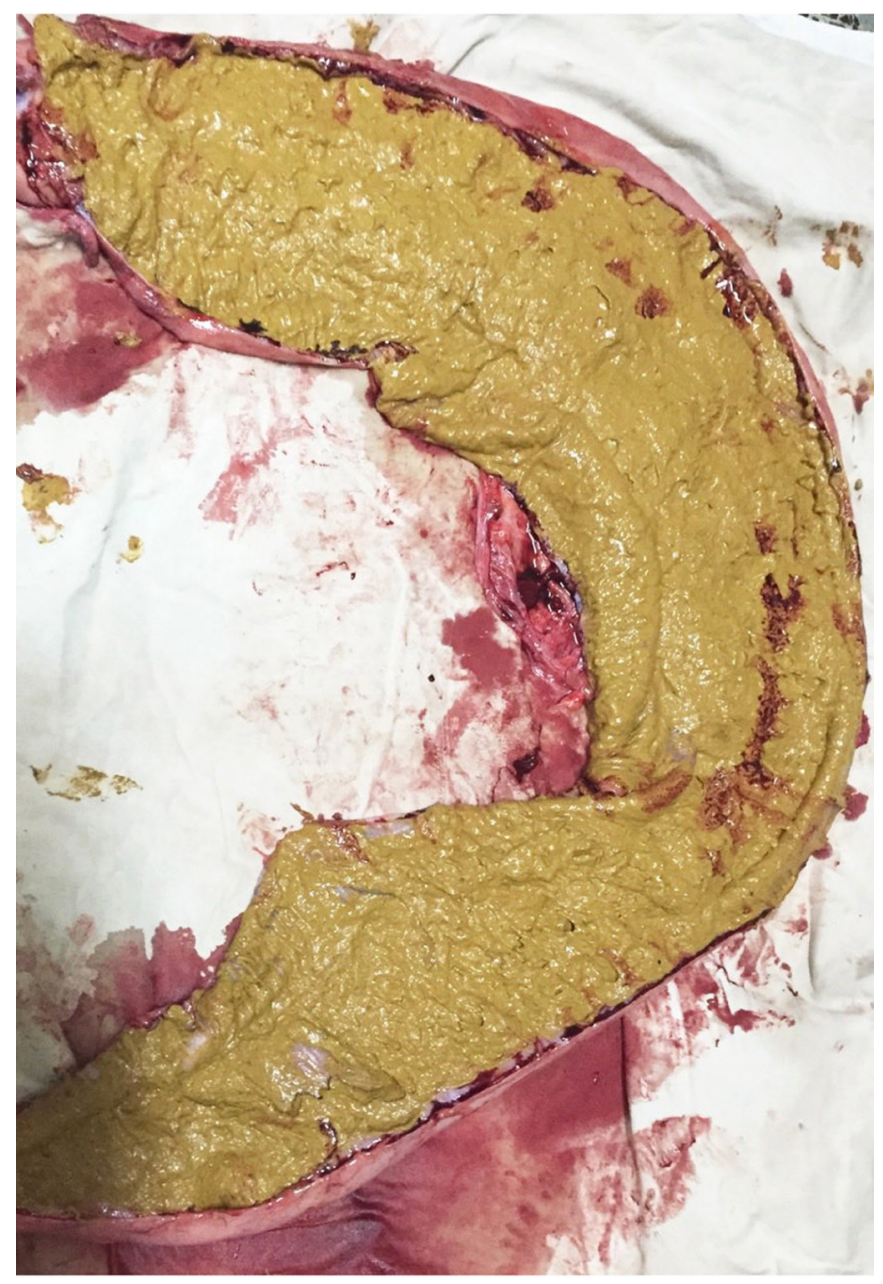

Figure 4 Cut surface of the resected specimen with impacted faecal material.

pseudo Hirschsprungs features, even prior to manifestation of medullary thyroid cancer. ${ }^{4}$

Gfroerer et al describe constipation (72\%) as the most common gastrointestinal symptom in patients with MEN2B. He evaluated 55 patients with MEN2B in published literature and

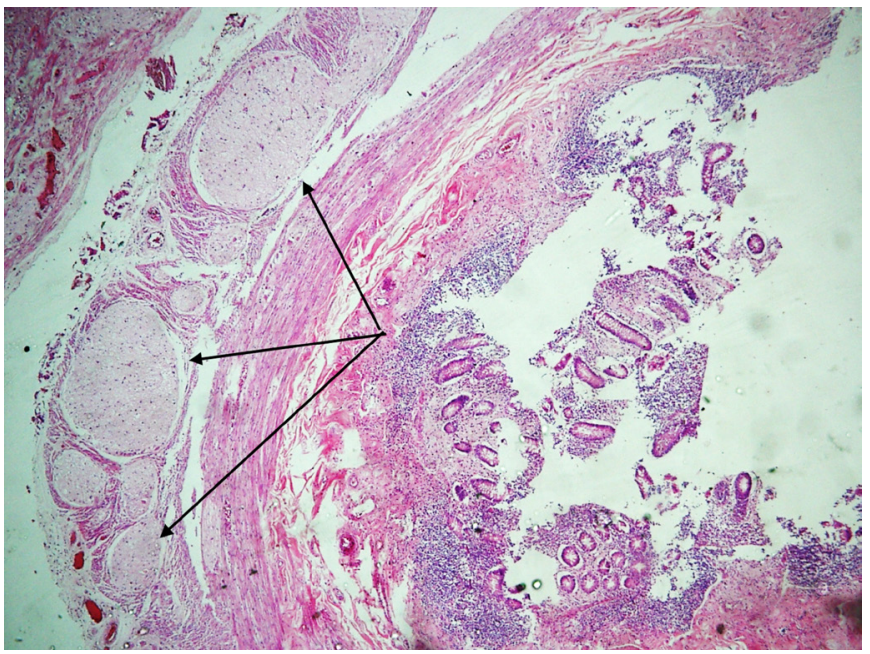

Figure 5 Histological specimen of patient showing hypertrophied nerve bundles (arrow heads)in the myenteric plexus.

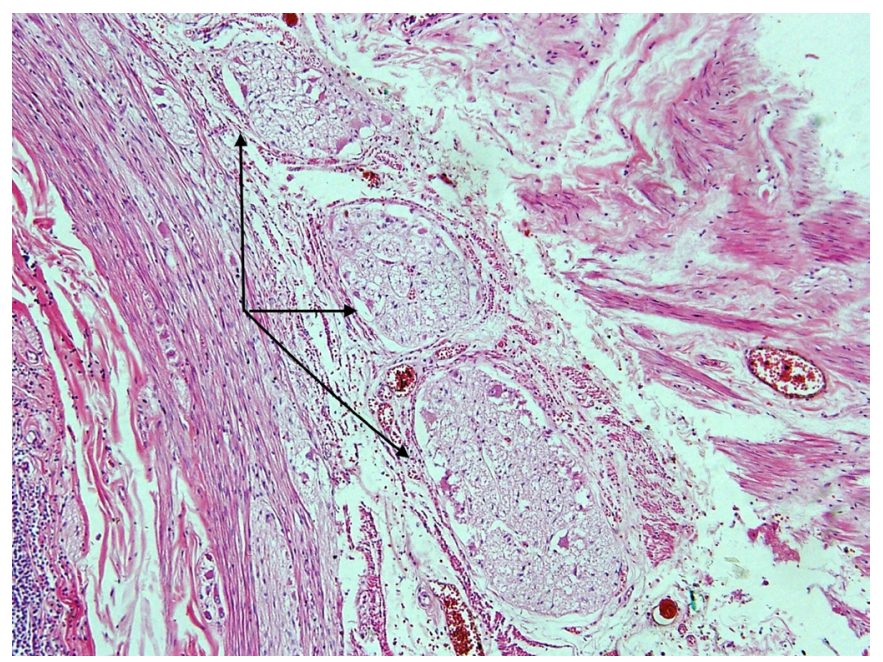

Figure 6 Magnified view of the hypertrophied nerve bundles in the myenteric plexus (arrow heads).

showed that more than $50 \%$ of patients presented with constipation below the age of 1 year. ${ }^{10}$

Huston et al described a case report where a 1-month baby who presented with constipation and was diagnosed with MEN2B following a rectal biopsy. The baby subsequently underwent a thyroidectomy at 9 months and a colectomy at 4 years. ${ }^{11}$ The presence of ganglions among enlarged nerve fibres distinguishes Hirschsprungs from MEN2B. ${ }^{12}$ Gibsons et al described 8 cases of megacolon out of 11 cases with MEN2B using the Mayo Clinic Registry over a period of 20 years. All of the reported cases with megacolon presented with constipation in early childhood or infancy. ${ }^{9}$

However, the unique presentation of our patient is that he presented late with troublesome constipation and megacolon at the age of 36 years. This presentation was even after being treated for disseminated medullary cancer at the age of 18 years at a tertiary care hospital. Our patient suffered from less than three bowel motions per week, straining during $25 \%$ of defecatory time, passing hard stools and also digitation to empty the rectum. These symptoms satisfy ROME IV criteria in the diagnosis of constipation which requires further evaluation. Despite having significant constipation for 3 months, the patient did not seek medical attention as he was from a rural area in Sri Lanka with limited access to tertiary healthcare facilities.

His clinically subtle constipation may have worsened by overt hypothyroidism caused by poor compliance to thyroxine. Therefore, a patient with MEN2B syndrome presenting with constipation, diffuse ganglioneuromatosis should be entertained in the differential diagnosis even in adults.

\section{Learning points}

- In most case reports, diffuse ganglioneuromatosis with MEN2B presents early in childhood with pseudo Hirschsprungs, even prior to manifestation of medullary thyroid cancer.

- Therefore, even among adults with multiple endocrine neoplasia syndrome presenting with constipation, diffuse ganglioneuromatosis should be considered in the differential diagnosis.

- The diagnosis of diffuse ganglioneuromatosis is confirmed by histology. 
Acknowledgements We would like to acknowledge the support rendered to us by Professor N R Perera and Dr L J De Silva of the Histopathology Department of Faculty of Medicine University of Colombo.

Contributors All authors contributed to the care of the patient. Dr ARF wrote the initial draft of the manuscript and Professor DNS and Dr RPB contributed with modifying the overall content in manuscript. All authors read and approved the manuscript.

Funding The authors have not declared a specific grant for this research from any funding agency in the public, commercial or not-for-profit sectors.

Competing interests None declared.

Patient consent Obtained.

Provenance and peer review Not commissioned; externally peer reviewed.

Open access This is an open access article distributed in accordance with the Creative Commons Attribution Non Commercial (CC BY-NC 4.0) license, which permits others to distribute, remix, adapt, build upon this work non-commercially, and license their derivative works on different terms, provided the original work is properly cited and the use is non-commercial. See: http://creativecommons.org/ licenses/by-nc/4.0/

\section{REFERENCES}

1 Smith VV, Eng C, Milla PJ. Intestinal ganglioneuromatosis and multiple endocrine neoplasia type 2B: implications for treatment. Gut 1999;45:143-6.
2 Lee YC, Wilson CJ, Winship IM, et al. dysmorphic features, and web neck. Southern medical journal 2000;93:1197-200.

3 Medscape. Medullary Thyroid Cancer and RET: background, clinical implications, testing for the genetic mutation: emedicine. 2016 http://emedicine.medscape.com/ article/1744824-overview

4 Chambonnière M-L, Porcheron J, Scoazec J-Y, et al. Intestinal ganglioneuromatosis diagnosed in adult patients. 2008.

5 National Comprehensive Cancer N. NCCN Clinical practice guidelines in oncology. 2011.

6 Laudari U, Rupakheti S, Bohara TP, et al. Isolated intestinal ganglioneuromatosis - a rare entity. Journal of Kathmandu Medical College 2017;5:131-5.

7 Godoy N, Parodi R, Díaz M, et al. Diffuse ganglioneuromatosis: infrequent pathology communication and review of literature. Acta Gastroenterol Latinoam 2010;40:151-5.

8 Fiori E, Pozzessere C, Lamazza A, et al. Endoscopic treatment of ganglioneuroma of the colon associated with a lipoma: a case report. J Med Case Rep 2012;6:1.

9 Gibbons D, Camilleri M, Nelson AD, et al. Characteristics of chronic megacolon among patients diagnosed with multiple endocrine neoplasia type 2B. United European Gastroenterol J 2016:4:449-54.

10 Gfroerer S, Theilen TM, Fiegel $\mathrm{H}$, et al. Identification of intestinal ganglioneuromatosis leads to early diagnosis of MEN2B: role of rectal biopsy. J Pediatr Surg 2017:52:1161-5.

11 Hutson JM, Farmer PJ, Peck CJ, et al. Multiple endocrine neoplasia 2B: differential increase in enteric nerve subgroups in muscle and mucosa. World J Gastrointest Pathophysiol 2017;8:142.

12 Yin M, King SK, Hutson JM, et al. Multiple endocrine neoplasia type 2B diagnosed on suction rectal biopsy in infancy: a report of 2 cases. Pediatr Dev Pathol 2006;9:56-60.

Copyright 2018 BMJ Publishing Group. All rights reserved. For permission to reuse any of this content visit https://www.bmj.com/company/products-services/rights-and-licensing/permissions/

BMJ Case Report Fellows may re-use this article for personal use and teaching without any further permission.

Become a Fellow of BMJ Case Reports today and you can:

- Submit as many cases as you like

- Enjoy fast sympathetic peer review and rapid publication of accepted articles

- Access all the published articles

Re-use any of the published material for personal use and teaching without further permission

For information on Institutional Fellowships contact consortiasales@bmjgroup.com

Visit casereports.bmj.com for more articles like this and to become a Fellow 